\title{
Evaluasi Sistem Informasi Manajemen Rumah Sakit Di Instalasi Rekam Medis RSUP H. Adam Malik Dengan Metode Human Organization Technology Fit (HOT-FIT) Tahun 2019
}

\author{
Welly Satria Dewi ${ }^{1}$, Daniel Ginting ${ }^{2}$, Rumondang Gultom ${ }^{3}$ \\ ${ }^{1,2,3}$ Program Studi Pasca Sarjana Magister Kesehatan Masyarakat, Universitas Sari Mutiara \\ Indonesia
}

\begin{tabular}{l} 
Article Info \\
\hline Article history: \\
Received Feb 05, 2021 \\
Revised Feb 20, 2021 \\
Accepted Feb 25, 2021 \\
\hline
\end{tabular}

Keywords:

Hospital Management Information System HOT Fit

\begin{abstract}
ABSTRAK
Based on the regulations of the Act - Act number 44-year 2009 about hospitals, where each hospital is obligated to do the recording and reporting of all activities of the Organization of the hospital in the form of hospital management information system (SIMRS). Therefore, every hospital is obligated to run SIMRS with the use of open source as has been set in the Year 2013 No. 82 Permenkes about SIMRS. The purpose of the study in order to evaluate the management information system in hospital medical record Installation was RSUP. Adam Malik. Quantitative research method withcross sectional design to measure the research variables model HOT Fit: Human (the use of the system, user satisfaction), Technology (quality system, the quality of information and service quality), Organization (structure), against a Net benefit. Population is the entire staff of medical record that uses SIMRS of 69 people, sampling techniques are the total sampling. The data analysis done in a multiple regression. The purpose of the study to find out the influence of the factor of human technology is preferred, and the organization's response to the net benefit. The results of the research there is the influence of human factors and technology against a net benefit to mean Ho denied and Ha was accepted, while to factor the organization has no influence on the net benefit, meaning that $\mathrm{Ho}$ and $\mathrm{Ha}$ accepted rejected. Simultaneously all the independent variables have significant effects on the dependent variable i.e. factors human, technology and organization, the impact on the net benefit. The R-squared value of 0.635 which means all variables the dependent variable may affect independent of $63.5 \%$. Conclusion the research need to craft a careful planning for the development of SIMRS in order to get a quality system, quality of information and service quality, and poured in the master plan, and strategic plan of the hospital.
\end{abstract}

\section{Corresponding Author:}

This is an open access article under the CC BY-SAlicense.

Welly Satria Dewi,

Program Studi Pasca Sarjana Magister Kesehatan Masyarakat,

Universitas Sari Mutiara Indonesia,

Jl. Kapten Muslim No.79 Medan, Sumatera Utara.

Email: bundadzakiya@gmail.com 


\section{PENDAHULUAN}

WHO (World Health Organization) mengenai e-health nomor WHA (World Health Assembly Resolution on e-health) nomor 58.28 Tahun 2005, WHO mendorong setiap negara untuk melakukan perencanaan serta implementasi layanan e-health dibidang kesehatan. E-health merupakan bidang ilmu yang berkembang dan merupakan perpaduan ilmu antara informatika medis, kesehatan masyarakat dan bisnis. E-health mengacu pada layanan kesehatan dan pemberian informasi kesehatan yang dikirimkan melalui jaringan internet dan teknologi terkait. Dalam pengertian yang lebih luas, istilah ini tidak hanya menandai perkembangan teknis, tapi juga pemikiran, cara berpikir, sikap, dan komitmen terhadap pemikiran global dan jaringan, dan mendunia dengan menggunakan teknologi informasi dan komunikasi, (Handayani dkk, 2018).

Di Indonesia telah diatur dalam UU No. 44 Tahun 2009 tentang rumah sakit, dimana setiap RS wajib melakukan pencatatan dan pelaporan tentang semua kegiatan penyelenggaraan RS dalam bentuk Sistem Informasi Manajemen Rumah Sakit (SIMRS). Oleh karenanya, setiap RS wajib menjalankan SIMRS dengan menggunakan open source seperti yang telah diatur dalam Permenkes No. 82 Tahun 2013 tentang SIMRS. Berdasarkan data dari Bagian Program dan Informasi, dari 2734 total keseluruhan RS, baru terdapat 1423 RS yang memiliki SIMRS dan berfungsi. Sedangkan, 134 diantara sudah memiliki SIMRS namun tidak berfungsi dan sebanyak 1177 RS masih belum memiliki SIMRS. Nantinya dengan adanya SIMRS dapat diketahui data analisis yang cepat untuk selanjutnya dapat digunakan untuk mendukung kebijakan regulasi di pusat, seperti kepengurusan BPJS, mengetahui data penyakit apa yang paling banyak diderita masyarakat, serta hal-hal lain terkait yang dapat digunakan sebagai data acuan pengambilan keputusan (Ditjen Yankes, 2017).

Pada laporan evaluasi pelaksanaan sistem informasi rumah sakit online (SIRS), provinsi Sumatera Utara tahun 2015 secara Nasional menduduki peringkat ke 29 (dua puluh sembilan). Pada tahun 2014 dari 166 rumah sakit yang sudah melakukan pelaporan SIRS Online hanya 23 rumah sakit yang memenuhi standar capaian 70\%, (Ditjen Yankes, 2015).

Evaluasi suatu sistem informasi adalah suatu usaha nyata untuk mengetahui kondisi sebenarnya suatu penyelenggaraan sistem informasi. Dengan evaluasi tersebut, capaian kegiatan penyelenggaraan suatu sistem informasi dapat diketahui dan tindakan lebih lanjut dapat direncanakan untuk memperbaiki kinerja penerapannya. Salah satu metode evaluasi menurut (Yusof et al., 2008) adalah HOT-Fit Model, dengan melihat secara keseluruhan sistem dengan menempatkan komponen penting dalam sistem informasi yakni manusia (human), organisasi (organization) dan teknologi (technology) dan kesesuaian hubungan diantaranya sebagai faktor-faktor penentu terhadap keberhasilan penerapan suatu sistem informasi, (Supriyono, 2016).

Hambatan yang terjadi yakni kurangnya pemahaman dan kepedulian sumber daya manusia dalam menjalankan fungsi, tugas dan tanggung jawabnya karena belum adanya tupoksi yang jelas, SPO dan edukasi serta sosialisasi yang belum optimal serta belum semua unit menggunakan SIMRS. Kurangnya personil untuk menangani permasalahan sistem. Pengguna langsung juga masih kurang memahami tentang cara penggunaan sistem. Pengguna tidak bisa mengimbangi tinggi tingkat teknologi dari SIMRS teramedik yang membuat terjadi gap pada saat implementasi (Nurlaila, 2017).

SIMRS harus selalu dilakukan evaluasi secara berkala, agar pengolahan data dan informasi yang dihasilkan akurat dan tepat waktu, diperlukan umpan balik dari user atau pengguna sebagai bahan evaluasi, perbaikan dan pengguna adalah orang yang paling mengetahui apakah SIMRS berjalan dengan baik dan menghasilkan informasi yang sesuai dengan kebutuhan pengguna. 
Berdasarkan informasi dari staf rekam medis pada aplikasi SIMRS masih banyak masalah yang ditemukan antara lain; loading kadang-kadang lama, pada bagian pelaporan masih banyak data/informasi yang berasal dari SIMRS harus diolah lagi secara manual, informasi/data masih ada yang tidak konsisten misalnya pada laporan morbiditas ataupun indek penyakit jumlah pasien atau kasus bisa berbeda padahal waktu pengambilan datanya hanya berbeda beberapa jam saja, apabila ada perubahan jumlah tempat tidur maka jumlah tempat tidur ditahun atau bulan sebelumnya otomatis juga ikut berubah, yang akhirnya berdampak pada angka BOR, untuk laporan SIRS 2011 petugas harus merubah dulu secara manual ke format yang ada di website Kementrian Kesehatan. Apabila ada masalah atau permintaan data yang tidak ada pada aplikasi SIMRS tidak bisa dieksekusi langsung, harus menunggu beberapa waktu karena vendor SIMRS berada di Jakarta. Untuk keamanan penggunaan aplikasi masih belum sempurna, walaupun semua user memiliki login dan passwood masing-masing akan tetapi apabila aplikasi sudah kita buka dan user lupa menutup dalam jangka waktu yang lama aplikasi itu akan tetap terbuka sehingga bisa kemungkinan dipergunakan oleh orang lain.

Dari segi manfaat SIMRS yang dimiliki RSUP H. Adam Malik sudah terintegrasi (bridging) dengan BPJS, sehingga mempercepat pelayanan pendaftaran pasien dan proses klaim pasien BPJS, walau pun demikian masih saja ada keterlambatan/pending klaim yang dialami pihak RSUP H. Adam Malik. Untuk pelaporan bulanan maupun tahunan yang dikirim ke pihak ekternal masih mengalami keterlambatan, seharusnya dikirim sebelum tanggal 10, tetapi pada kenyataannya dikirim diatas tanggal 10 setiap bulannya. RSUP H. Adam Malik juga belum pernah melakukan evaluasi secara berkala terhadap SIMRS khususnya di Instalasi Rekam Medis. Evaluasi SIMRS mengandung maksud untuk mengidentifikasi kekuatan dan kelemahan dari SIMRS yang sedang digunakan.

Evaluasi juga bertujuan untuk mengetahui tersedia tidaknya suatu informasi saat diperlukan, benar-benar tersaji bagi yang berhak, dan juga untuk mengetahui bahwa informasi yang diberikan dalam aplikasi disajikan secara akurat, handal, dan tepat waktu. Atas dasar uraian diatas, peneliti akan melakukan penelitian dengan judul "Evaluasi Sistem Informasi Manajemen Rumah Sakit di Instalasi Rekam Medis RSUP H. Adam Malik dengan Metode Human Organization Technology Fit (HOT Fit)".

\section{METODE PENELITIAN}

A. Jenis Penelitian

Jenis penelitian ini menggunakan metode penelitian deskriptif kuantitatif dengan rancangan penelitian cross sectional untuk mengetahui pengaruh variabel independen (human, technology, organization) terhadap variabel dependen (net benefit). Waktu penelitian ini akan dilakukan pada bulan Desember 2018 s.d Mei 2019. Tempat penelitian dilakukan di RSUP H. Adam Malik, khususnya di Instalasi Rekam Medis, yang berlokasi di Jl. Bunga Lau No 17 Medan Tuntungan.

B. Sampel Penelitian

Sampel adalah objek yang diteliti dan dianggap mewakili seluruh populasi (Notoatmodjo, 2017). Teknik pengambilan sampel dalam penelitian ini adalah total sampling. Total Sampling adalah Teknik pengambilan sampel dimana jumlah sampel sama dengan populasi (Sugiyono, 2007). Alasan mengambil total sampling karena menurut (Sugiyono, 2017) jumlah populasi yang kurang dari 100 seluruh populasi dijadikan sampel penelitian semuanya.Sampel yang diambil dalam penelitian adalah 69 orang.

C. Variabel Penelitian

Penelitian ini menggunakan model HOT-Fit yang dikembangkan oleh (Yosuf at.el, 2006 dalam Kadarisman, 2013) dengan beberapa modifikasi untuk menilai keberhasilan penerapan sistem informasi manajemen rumah sakit. Pada penelitian ini variabel organisasi yang dinilai hanya struktur organisasi, sedangkan lingkungan 
organisasi tidak dinilai. Defenisi dan konsep variabel/dimensi HOT-Fit yang digunakan dalam penelitian ini dapat dijelaskan sebagai berikut:

1. Variabel independen antara lain :

a. Human (penggunaan sistem, kepuasaan pengguna)

b. Technologi (kualitas sistem, kualitas informasi, kualitas layanan)

c. Organization (stuktur organisasi)

2. Variabel dependen: Net benefit

D. Definisi Operasional

Tabel 1. Definisi Operasional

\begin{tabular}{|c|c|c|}
\hline No & Indikator & Defenisi Operasional \\
\hline \multirow[t]{2}{*}{1} & Penggunaan Sistem & $\begin{array}{l}\text { Penggunaan sistem berkaitan dengan tingkat } \\
\text { penggunaan sistem, harapan terhadap sistem dan } \\
\text { penerimaan/penolakan pengguna }\end{array}$ \\
\hline & $\begin{array}{l}\text { Kepuasan } \\
\text { Pengguna }\end{array}$ & $\begin{array}{l}\text { Penilaian secara menyeluruh mengenai pengalaman } \\
\text { dalam menggunakan sistem, dapat dihubungkan } \\
\text { dengan sikap pengguna dan persepsi pengguna } \\
\text { terhadap manfaat sistem }\end{array}$ \\
\hline \multirow[t]{3}{*}{2} & Kualitas Sistem & $\begin{array}{l}\text { Kinerja sistem termasuk didalamnya kemudahan } \\
\text { penggunaan fitur, kemanan system, hak akses, jarang } \\
\text { error, terintegrasi kesemua unit }\end{array}$ \\
\hline & Kualitas Informasi & $\begin{array}{l}\text { Informasi yang dihasilkan oleh sistem, sesuai dengan } \\
\text { kebutuhan, mudah dipahami, akurat, valid, tepat } \\
\text { waktu, konsisten, berperan dalam pengambilan } \\
\text { keputusan }\end{array}$ \\
\hline & Kualitas Layanan & $\begin{array}{l}\text { Layanan pendukung dari unit kerja (teknologi } \\
\text { informasi) di dalam rumah sakit maupun dari penyedia } \\
\text { jasa eksternal (vendor), yaitu cepat Menanggapi } \\
\text { permasalahan, jaminan pelayanan, menyelesaikan } \\
\text { keluhan/ tindak lanjut terhadap keluhan dan empati. }\end{array}$ \\
\hline 3 & Struktur Organisasi & $\begin{array}{l}\text { Situasi organisasi termasuk didalamnya budaya } \\
\text { organisasi, besaran kapasitas organisasi, perencanaan } \\
\text { dan pengendalian, tingkatan dalam struktur organisasi, } \\
\text { otonomi, kepemimpinan, dukungan dari pimpinan } \\
\text { organisasi, }\end{array}$ \\
\hline 4 & Net Benefit & $\begin{array}{l}\text { Manfaat yang dirasakan baik pengguna mapun } \\
\text { pelanggan dan lintas sektoral terkait dengan informasi } \\
\text { di RS dalam meningkatkan kinerja dan pelayanan RS }\end{array}$ \\
\hline
\end{tabular}

E. Cara Penelitian

Penelitian dilakukan dalam tiga tahap yaitu:

1) Survey melalui kuesioner tertutup

2) Wawancara

3) Observasi data dan dokumen

F. Uji Validitas dan Reliabilitas

Uji reliabilitas dapat dilihat dari nilai Cronbach's Alpha dan Composite Reliability. Untuk dapat dikatakan reliable maka nilai Cronbach's Alpha harus >0,6. Nilai Cronbach's Alpha untuk seluruh variabel > 0,799 sehingga dapat dinyatakan reliable. Hasil uji didapatkan nilai ir-cor di atas nilai $r$ tabel. Dimana nilai $r$ pada tabel $\mathrm{r}$ dengan derajat bebas $\mathrm{n}-2$ dimana $\mathrm{n}$ adalah jumlah responden sebanyak 20 orang, sehingga nilai yang digunakan dalam penelitian ini adalah tabel $\mathrm{r}$ dengan derajat bebas 18 dan diperoleh nilai 0.444. Pertanyaan valid adalah yang 
mempunyai ircor di atas nilai $\mathrm{r}$ tabel antara lain untuk variabel pengguna sistem nilai 0.447-0.592, untuk variabel kepuasan pengguna nilai 0.545-0.678, untuk variabel kualitas system nilai $0.492-0.739$, untuk variabel kualitas informasi nilai 0.458-0.743, untuk variabel kualitas layanan nilai $0.479-0.786$, variabel struktur organisasi nilai 0.523-0.842 dan Net benefit nilai 0.494-0.758.

G. Analisa Data

1. Univariat, setelah ditabulasi data kemudian dianalisis dengan statistika deskriptif kemudian disajikan dalam tabel distribusi frekuensi.

2. Multivariat, dilakukan untuk mengetahui pengaruh faktor human, technology dan organization terhadap net benefit dengan menggunakan analisis regresi berganda.

\section{HASIL DAN PEMBAHASAN}

\subsection{Hasil}

\section{Faktor Human}

Faktor Human dilihat dari persepsi responden terkait penggunaan sistem dan kepuasan pelanggan terhadap SIMRS.

Tabel 2. Faktor Human (Penggunaan Sistem Dan Kepuasan Pelanggan)

\begin{tabular}{|c|c|c|c|c|c|c|}
\hline Variabel & Indikator & SS & $\mathrm{S}$ & $\mathrm{N}$ & $\mathrm{TS}$ & STS \\
\hline Human & & & & $\%$ & & \\
\hline \multirow{6}{*}{$\begin{array}{l}\text { Penggunaan } \\
\text { Sistem }\end{array}$} & SIMRS mudah digunakan & 49.28 & 30.43 & 13.04 & 7.25 & 0.0 \\
\hline & meningkatkan mutu pelayanan & 30.43 & 47.83 & 13.04 & 8.70 & 0.0 \\
\hline & pelayanan yang cepat dan efektif & 15.94 & 68.12 & 15.94 & 0.00 & 0.0 \\
\hline & mengurangi angka kesalahan & 13.04 & 43.48 & 30.43 & 13.04 & 0.0 \\
\hline & $\begin{array}{l}\text { membantu pengambilan } \\
\text { keputusan }\end{array}$ & 0.00 & 33.33 & 31.88 & 34.78 & 0.0 \\
\hline & mencegah duplikasi data & 15.94 & 50.72 & 33.33 & 0.00 & 0.0 \\
\hline \multirow[t]{6}{*}{$\begin{array}{l}\text { Kepuasan } \\
\text { pengguna }\end{array}$} & $\begin{array}{l}\text { Fasilitas dan fitur-fitur sesuai } \\
\text { dengan kebutuhan pengguna }\end{array}$ & 18.84 & 42.03 & 23.19 & 15.94 & 0.0 \\
\hline & $\begin{array}{l}\text { Informasi/data yang dihasilkan } \\
\text { sesuai dengan kebutuhan } \\
\text { pengguna }\end{array}$ & 0.00 & 40.58 & 10.14 & 49.28 & 0.0 \\
\hline & mudah dan aman digunakan & 24.64 & 59.42 & 15.94 & 0.00 & 0.0 \\
\hline & $\begin{array}{l}\text { Memudahkan untuk memperoleh } \\
\text { informasi yang lebih banyak }\end{array}$ & 13.04 & 76.81 & 10.14 & 0.00 & 0.0 \\
\hline & Membantu mengolah informasi & 13.04 & 86.96 & 0.00 & 0.00 & 0.0 \\
\hline & Mempercepat pekerjaan & 24.64 & 52.17 & 8.70 & 14.49 & 0.0 \\
\hline
\end{tabular}

\section{Faktor Technology}

Faktor Technology dilihat dari persepsi responden terhadap kualitas sistem, kualitas informasi dan kualitas layanan SIMRS.

Tabel 3. Faktor Tecnology (Kualitas Sistem, Kualitas Informasi dan Kualitas Layanan)

\begin{tabular}{llccccc}
\hline \multicolumn{1}{c}{ Variabel } & \multicolumn{1}{c}{ Indikator } & SS & S & N & TS & STS \\
\hline Tecnology & & & & \% & & \\
\hline Kualitas & Mudah untuk digunakan & 13,04 & 86,96 & 0,00 & 0,00 & 0.0 \\
\cline { 2 - 7 } Sistem & Terintegrasi kesemua unit/SMF & 39,13 & 60,87 & 0,00 & 0,00 & 0.0 \\
\cline { 2 - 7 } & Terintegrasi dengan BPJS & 55,07 & 44,93 & 0,00 & 0,00 & 0.0 \\
\cline { 2 - 7 } & User memiliki password sendiri & 68,12 & 31,88 & 0,00 & 0,00 & 0.0 \\
\hline
\end{tabular}




\begin{tabular}{|c|c|c|c|c|c|c|}
\hline & $\begin{array}{l}\text { Informasi/data hanya bisa diakses } \\
\text { oleh pihak yang memiliki } \\
\text { kewenangan }\end{array}$ & 28,99 & 30,43 & 17,39 & 24,64 & 0.0 \\
\hline & Jarang error & 0,00 & 11,59 & 31,88 & 56,52 & 0.0 \\
\hline & $\begin{array}{l}\text { Tersedianya buku panduan petunjuk } \\
\text { dan instruksi untuk pengguna }\end{array}$ & 0,00 & 10,14 & 24,64 & 65,22 & 0.0 \\
\hline & $\begin{array}{l}\text { menghasilkan informasi yang } \\
\text { konsisten }\end{array}$ & 0,00 & 28,99 & 24,64 & 46,38 & 0.0 \\
\hline \multirow[t]{6}{*}{$\begin{array}{l}\text { Kualitas } \\
\text { Informasi }\end{array}$} & $\begin{array}{l}\text { Smenyediakan informasi } \\
\text { dengan kebutuhan pengguna }\end{array}$ & 0,00 & 79,71 & 13,04 & 7,25 & 0.0 \\
\hline & $\begin{array}{l}\text { Informasi yang dihasilkan mudah } \\
\text { dipahami }\end{array}$ & 13,04 & 86,96 & 0,00 & 0,00 & 0.0 \\
\hline & $\begin{array}{l}\text { Informasi yang dihasilkan akurat } \\
\text { dan tepat waktu }\end{array}$ & 13,04 & 37,68 & 18,84 & 30,43 & 0.0 \\
\hline & $\begin{array}{l}\text { Informasi/data yang } \\
\text { selalu dalam keadaan } \\
\text { konsisten }\end{array}$ & 0,00 & 28,99 & 24,64 & 46,38 & 0.0 \\
\hline & $\begin{array}{lr}\text { Informasi/data yang } & \text { dihasilkan } \\
\text { bermanfaat } & \text { untuk } \\
\text { Pendidikan/penelitian } & \end{array}$ & 28,99 & 44,93 & 15,94 & 10,14 & 0.0 \\
\hline & $\begin{array}{l}\text { Informasi/data berperan dalam } \\
\text { pengambilan keputusan oleh pihak } \\
\text { manajemen }\end{array}$ & 28,99 & 62,32 & 8,70 & 0,00 & 0.0 \\
\hline \multirow[t]{6}{*}{$\begin{array}{l}\text { Kualitas } \\
\text { Layanan }\end{array}$} & $\begin{array}{l}\text { Layanan dari vendor/pengelola } \\
\text { cepat jika dibutuhkan bantuan }\end{array}$ & 28,99 & 59,42 & 11,59 & 0,00 & 0.0 \\
\hline & $\begin{array}{l}\text { Vendor menyelesaikan masalah } \\
\text { yang dihadapi sampai selesai }\end{array}$ & 13,04 & 37,68 & 8,70 & 42,03 & 0.0 \\
\hline & $\begin{array}{l}\text { Tersedianya buku panduan petunjuk } \\
\text { dan instruksi untuk pengguna }\end{array}$ & 0,00 & 10,14 & 13,04 & 76,81 & 0.0 \\
\hline & $\begin{array}{l}\text { Ada unit khusus yang bertugas } \\
\text { mengelola SIMRS }\end{array}$ & 40,58 & 59,42 & 0,00 & 0,00 & 0.0 \\
\hline & $\begin{array}{l}\text { Pemeliharaan perangkat keras } \\
\text { SIMRS secara berkala }\end{array}$ & 24,64 & 50,72 & 24,64 & 0,00 & 0.0 \\
\hline & $\begin{array}{l}\text { Memiliki nomor vendor/pengelola } \\
\text { yang bisa dihubungi jika terjadi } \\
\text { masalah }\end{array}$ & 17,39 & 82,61 & 0,00 & 0,00 & 0.0 \\
\hline
\end{tabular}

\section{Faktor Oragnization}

Faktor Organization dilihat dari persepsi responden terhadap dukungan struktur organisasi terhadap SIMRS.

Tabel 4. Faktor Oragnization

\begin{tabular}{clcccccc}
\hline \multicolumn{1}{c}{ Variabel } & SS & S & N & TS & STS \\
\hline Struktur Organisasi & & & & \% & & \\
\hline & $\begin{array}{l}\text { SIMRS diterapkan } \\
\text { meningkatkan kinerja }\end{array}$ & untuk & 24.64 & 75.36 & 0.0 & 0.0 & 0.0 \\
\hline $\begin{array}{l}\text { Perangkat hardware \& software } \\
\text { selalu diperbaharui }\end{array}$ & 17.39 & 82.61 & 0.0 & 0.0 & 0.0 \\
\hline $\begin{array}{l}\text { Pihak manajemen RS melakukan } \\
\text { pelatihan terkait dengan SIMRS. }\end{array}$ & 13.04 & 75.36 & 11.59 & 0.0 & 0.0 \\
\hline
\end{tabular}


$\begin{array}{llllll}\text { Memiliki Kebijakan dan SPO yang } & 0.0 & 72.46 & 27.54 & 0.0 & 0.0\end{array}$ terkait dengan SIMRS

$\begin{array}{lllllll}\text { Pengguna dilibatkan dalam proses } & 0.0 & 23.19 & 28.99 & 47.83 & 0.0\end{array}$ perencanaan dan pengembangan

SIMRS

$\begin{array}{llllllll}\text { Tingkat } & \text { kepuasan } & \text { pengguna } & 0.0 & 46.38 & 0.00 & 53.62 & 0.0\end{array}$

SIMRS di evaluasi secara berkala

$\begin{array}{llllllll}\text { Adanya komitmen dari pihak } & 0.0 & 84.06 & 15.94 & 0.0 & 0.0\end{array}$

manajemen dalam penggunaan

SIMRS

$\begin{array}{llllllll}\text { Data/informasi } & \text { dari } & \text { SIMRS } & 18.84 & 68.12 & 13.04 & 0.0 & 0.0\end{array}$

berperan dalam pengambilan

keputusan bagi pihak manajemen

\section{Variabel Dependen (Net Benefit)}

Faktor net benefit dalam penelitian ini terkait dengan manfaat yang dirasakan baik pengguna mapun pelanggan dan lintas sektoral terkait dengan informasi di RS dalam meningkatkan kinerja dan pelayanan RS.

Tabel 5. Faktor Net Benefit

\begin{tabular}{|c|c|c|c|c|c|c|}
\hline \multirow{2}{*}{\multicolumn{2}{|c|}{$\begin{array}{c}\text { Variabel } \\
\text { Net Benefit }\end{array}$}} & SS & $\mathrm{S}$ & $\mathrm{N}$ & TS & STS \\
\hline \multirow[t]{17}{*}{ Net Benefit } & & \multicolumn{5}{|c|}{$\%$} \\
\hline & SIMRS memudahkan dalam & 23.19 & 78.81 & 0.0 & 0.0 & 0.0 \\
\hline & \multicolumn{6}{|l|}{ mengukur respon time rekam medis } \\
\hline & SIMRS memudahkan dalam & 28.99 & 37.68 & 14.49 & 14.84 & 0.0 \\
\hline & $\begin{array}{l}\text { mengukur indikator mutu rekam } \\
\text { medis }\end{array}$ & & & & & \\
\hline & SIMRS meningkatkan & 21.74 & 62.32 & 15.94 & 0.0 & 0.0 \\
\hline & pelayanan rekam medis & & & & & \\
\hline & $\begin{array}{l}\text { SIMRS menjadikan pelayanan rekam } \\
\text { medis yang cepat dan efektif }\end{array}$ & 13.04 & 69.57 & 8.70 & 8.70 & 0.0 \\
\hline & SIMRS mempercepat proses klaim & 0.0 & 42.03 & 8.70 & 49.28 & 0.0 \\
\hline & BPJS & & & & & \\
\hline & SIMRS bermanfaat dalam & 13.04 & 71.01 & 15.94 & 0.0 & 0.0 \\
\hline & perencanaan dan evaluasi program & & & & & \\
\hline & $\begin{array}{l}\text { SIMRS bermanfaat bagi pendidikan } \\
\text { dan penelitian }\end{array}$ & 28.99 & 44.93 & 15.94 & 10.14 & 0.0 \\
\hline & $\begin{array}{l}\text { Pengiriman laporan SIRS menjadi } \\
\text { tepat waktu }\end{array}$ & 0.0 & 28.99 & 28.99 & 42.03 & 0.0 \\
\hline & SIMRS mewujudkan visi dan misi RS & 18.84 & 56.52 & 24.64 & 0.0 & 0.0 \\
\hline & SIMRS meningkatkan kinerja RS & 23.19 & 68.12 & 8.70 & 0.0 & 0.0 \\
\hline & $\begin{array}{l}\text { SIMRS mempermudah pengiriman } \\
\text { laporan RS }\end{array}$ & 53.62 & 31.88 & 14.49 & 0.0 & 0.0 \\
\hline
\end{tabular}

\section{Hasil Analisis Statistik}

Hasil analisis regresi liner berganda faktor human (X1), faktor technology (X2), faktor organization (X3) terhadap faktor net benefit (Y) dapat dilihat pada tabel 6 dibawah ini. 
Tabel 6. Analisis Statistik

\begin{tabular}{lcccc}
\hline \multicolumn{1}{c}{ Variabel } & $\mathrm{B}$ & Beta & $\mathrm{t}$ & Sig \\
\hline Constant & -11.435 & & -2.244 & 0.028 \\
\hline Human $(\mathrm{X} 1)$ & -0.504 & -0.578 & -3.572 & 0.001 \\
\hline Technology $(\mathrm{X} 2)$ & 0.947 & 1.222 & 7.504 & 0.000 \\
\hline Organization $(\mathrm{X} 3)$ & 0.063 & 0.040 & 0.355 & 0.739 \\
\hline Y & & & \\
\hline F & 37.165 & & \\
\hline Sig & & 0.000 & & \\
\hline R-Square & 0.635 & & \\
\hline
\end{tabular}

\subsection{Pembahasan}

\section{Pengaruh Faktor Human Terhadap Net Benefit}

Dari hasil uji regresi berganda diperoleh nilai t hitung untuk faktor human (X1) sebesar $-3,572$ dengan nilai signifikan sebesar $0,001<0,05$ yang berarti faktor human berpengaruh terhadap net benefit. Dari hasil analisa univariat (tabel 2) didapatkan sebanyak $34,78 \%$ responden tidak setuju penggunaan SIMRS dapat membantu pengambilan keputusan. Sebanyak 40,58\% responden tidak setuju dengan pernyataan informasi/data yang dihasilkan sesuai dengan kebutuhan pengguna.

SIMRS mempunyai peranan yang penting bagi pihak manajemen rumah sakit, SIMRS membantu seorang direktur rumah sakit dalam mengambil suatu kebijakan/keputusan secara cepat, tepat sesuai dengan informasi yang dihasilkan SIMRS. Apabila informasi yang dihasilkan SIMRS akurat dan konsisten pihak direksi akan lebih mudah dalam mengambil keputusan untuk perencanaan dan pengembangan rumah sakit kedepannya, misalnya rumah sakit ingin menambah alat Echocardiografi, sebelum alat ini dibeli direktur harus melihat terlebih dahulu apakah jumlah pasien dengan diagnosa penyakit jantung memang banyak, apabila dalam pengambilan keputusan ini tidak melihat informasi dari SIMRS bisa saja nanti alat yang sudah ada tidak bermanfaat dan tidak bisa menutupi biaya operasional yang diakibatkan oleh pengadaan alat tersebut.

Sebelum melakukan pengembangan SIMRS pihak manajemen rumah sakit tidak hanya memilih vendor yang berpengalaman, akan tetapi yang lebih penting adalah melibatkan pengguna SIMRS, vendor harusnya terlebih dahulu melakukan maping data untuk mengetahui aplikasi apa saja yang diperlukan oleh pengguna agar informasi yang dihasilkan SIMRS bermanfaat dan bisa memenuhi kebutuhan pengguna.

\section{Pengaruh Faktor Technology Terhadap Net Benefit}

Berdasarkan analisis regresi berganda (tabel 6) didapatkan nilai t hitung untuk faktor technology (X2) 7,504 dengan nilai signifikan 0,000 < 0,05 yang berarti faktor technology berpengaruh terhadap net benefit. Dari hasil analisa univariat terhadap kualitas sistem (tabel 3) didapatkan sebanyak 56,52\% responden tidak setuju SIMRS jarang error, sebanyak $65,22 \%$ responden tidak setuju tersedianya buku panduan petunjuk dan instruksi untuk pengguna, 46,38 \% responden tidak setuju SIMRS menghasilkan informasi yang konsisten. Hal ini menunjukkan bahwa SIMRS masih sering error, tidak tersedianya buku petunjuk dan informasi yang dihasilkan tidak konsisten.

Menurut (Rustiyanto, 2010), Faktor penghambat pengembangan sistem manajemen informasi meliputi faktor teknis dan non teknis. Faktor penghambat dari faktor teknis terletak pada aspek hardware dan software yaitu pada koneksi jaringannya akibat instalasi yang tidak sempurna bukan pada spesifikasi teknis kemampuan teknik komputernya. Aspek database juga merupakan salah satu dari faktor teknis dimana data tidak bisa terintegrasi dengan bagian lain. Faktor penghambat dari aspek non teknis atara lain tidak 
memiliki tim dan tenaga teknisi, motivasi dan kualitas SDM pengguna yang rendah, pihak pengembang SIM belum memiliki struktur organisasi, prosedur kerja serta manajemen proyek yang kurang baik.

Pihak vendor/instalasi SIRS perlu mengadakan buku pedoman instruksi untuk pengguna agar pengguna bisa memanfaatkan SIMRS secara maksimal. Dengan adanya buku pedoman pengguna akan mengetahui dan mengoptimalkan fungsi-fungsi dan fitur apa saja yang ada pada SIMRS, mendapatkan manfaat yang maksimal dari SIMRS, menghindari resiko kesalahan dan mengetahui cara mengatasi masalah yang ada pada SIMRS.

\section{Pengaruh Faktor OrganizationTerhadap Net Benefit}

Dari analisis regresi berganda didapatkan nilai t hitung untuk faktor organization (X3) 0,355 dengan nilai signifikan $0,739>0,05$ yang berarti faktor organization tidak berpengaruh terhadap net benefit. Dari uraian kuisioner (tabel 4) 47,83\% responden tidak setuju pengguna dilibatkan dalam proses perencanaan dan pengembangan SIMRS, 53,62\% responden tidak setuju tingkat kepuasan pengguna SIMRS dievaluasi secara berkala.

Didalam proses merancang modul/menu SIMRS, manajemen RSUP H. Adam Malik dapat melibatkan pengguna SIMRS dalam menentukan input, proses sampai dengan outputnya agar sesuai dengan keinginan dan kebutuhan dari masing-masing pengguna, tidak hanya membeli aplikasi yang sudah jadi dari vendor, sehingga banyak outputnya tidak sesuai dengan kebutuhan rumah sakit. Apabila ada pengembangan dalam SIMRS maka pengguna perlu diberikan pelatihan ulang guna mensosialisasikan dan melatih pengguna agar SIMRS benar-benar bisa dijalankan dengan maksimal dan informasi yang dihasilkan bermanfaat bagi semua pihak.

\section{KESIMPULAN}

1. Semua variabel independen faktor human, faktor technology, dan faktor organization secara simultan mempunyai pengaruh terhadap net benefit, dengan nilai R-square 0,635 atau $63.5 \%$.

2. Faktor human (penggunaan sistem dan kepuasan pengguna) berpengaruh terhadap net benefit dalam SIMRS di RSUP H. Adam Malik. Hal ini berarti semakin meningkat penggunaan sistem dan kepuasan pengguna semakin tinggi net benefit yang didapatkan dari penggunaan SIMRS.

3. Faktor technology (kualitas sistem, kualitas informasi dan kualitas layanan) berpengaruh terhadap net benefit dalam SIMRS di RSUP H. Adam Malik. Hal ini berarti semakin tinggi kualitas system, kualitas informasi dan kualitas layanan semakin tinggi net benefit yang didapatkan dari penggunaan SIMRS.

4. Faktor organization (struktur organisasi) tidak berpengaruh terhadap net benefit dalam SIMRS RSUP H. Adam Malik apabila diuji secara parsial.

\section{REFERENCES}

Ditjen Yankes Kemekes.2015.Laporan Evaluasi Pelaksanaan SIRS Online Provinsi Sumatera Utara. https://dokumen.tips/download/link/laporan-evaluasi-pelaksanaansirs-online-propinsi-sumatera-utara-tahun-2015, diakses 20 Januari 2019).

Ditjen Yankes Kemekes. 2017. Tahun 2018, sетиa rumah sakit harus sudah mempunyai SIMRR terintegrasi. (http://yankes.kemkes.go.id/read-tahun-2018-semua-rumah-sakitharus-sudah-punya-simrs-terintegrasi-2647.html, diakses 20 Januari 2019).

Handayani, PW \& dkk. 2018. Pengantar Sistem Informasi Manajemen Rumah Sakit (SIMRS). Depok: Raja Grafindo Persada. 
Kodarisman, K \& Nugroho, E. 2013. Evaluasi Penerapan Sistem Informasi Manajemen Kepegawaian (SIMPEG) di Pemerintah Kota Bogor. Jurnal JNTETI, Vol 2 No. 2, 2432.

Krisbiantoro, Dwi, dkk. 2015. Evaluasi Keberhasilan Implementasi Sistem informasi Dengan Pendekatan HOT FIT Model (Studi Kasus: Perpustakaan STMIK AMIKOM Purwokerto). Konferensi Nasional Sistem \& Informatika 2015: STMIK AMIKOM Bali.

Notoatmodjo, S. 2017. Metodologi Penelitian Kesehatan. Jakarta: Rineka Cipta.

Nurlaila, Titin. 2016. Evaluasi Implementasi Sistem Informasi Manajmen Rumah Sakit (SIMRS) Di RSIA Keluarga Kita Curug Tanggerang Menggunakan HOT FIT Model. Tesis: Universitas Gadjah Mada.

Presiden RI. 2009. Undang-Undang Nomor 44 Tahun 2009 Tentang Rumah Sakit.

RSUP H. Adam Malik. 2018. Profil RSUP H. Adam Malik Tahun 2017. Medan: RSUP H. Adam Malik.

Rustiyanto, Ery. 2010. Sistem Informasi Manajemen Rumah Sakit Yang Terintegrasi. Yogyakarta: Gosyen Publishing.

Sugiyono. 2017. Metode Penelitian Kuantitatif, Kualitatif dan R\&D. Bandung: Alfabeta.

Supriyono. 2016. Evaluasi Sistem Informasi Manajemen Rumah Sakit Dengan Metode HOT Fit Di Rumah Sakit Umum Daerah Raden Mattaher Jambi. Tesis: Universitas Gadjah Mada.

Yusof, M.M., at al. 2008. An Evaluation Framework For Health Information System : Human, Organization, Technology-Fit Factors (HOT-Fit). Internasional Journal of Medical Informastic, 77 (6), pp.386-398.

\section{BIOGRAPHIES OF AUTHORS}

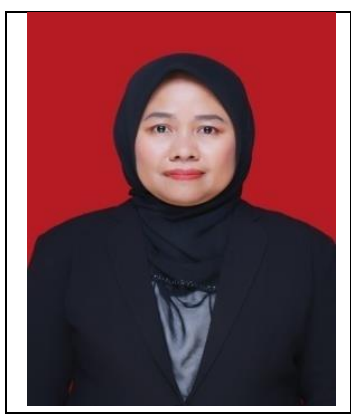

Welly Satria Dewi, gelar Sarjana diperolah dari Stikes Sumatera Utara pada tahun 2008 dan Politeknik Piksi Ganesha Bandung pada tahun 2013. Magister Kesehatan Masyarakat diperoleh dari Universitas Sari Mutiara Indonesia pada tahun 2019. Saat ini aktif bekerja di RSUP H. Adam Malik dan aktif mengajar di Program Studi D III Rekam Medis Universitas Imelda Medan. 